\title{
Amino Acid Characteristics between Jeju Black Cattle, Hanwoo, and Wagyu Breeds
}

\author{
Seung-Hoon Lee ${ }^{1,{ }^{\dagger}}$, Chung-Nam Kim ${ }^{2,+}$, Kyoung-Bo Ko ${ }^{2}$, Se-Pill Park ${ }^{2}$, \\ Ho-Kyoung Kim ${ }^{3}$, Jun-Mo Kim ${ }^{4,}$, and Youn-Chul Ryu ${ }^{2, *}$ \\ ${ }^{1}$ Division of Biotechnology, College of Life Science, Korea University, Seoul 02841 , \\ Korea \\ 2Division of Biotechnology, SARI, Jeju National University, Jeju 63243, Korea \\ ${ }^{3}$ Division of Food Nutrition and Culinary Art, Dong-Eui Institute of Technology, Busan \\ 47230, Korea \\ ${ }^{4}$ Department of Animal Science and Technology, College of Biotechnology and \\ Natural Resources, Chung-Ang University, Anseong 17546, Korea
}

*Corresponding author : Jun-Mo Kim Department of Animal Science and Technology, College of Biotechnology and Natural Resources, Chung-Ang University, Anseong 17546, Korea

Tel: +82-31-670-3263

Fax: +82-31-675-3108

E-mail: junmokim@cau.ac.kr

Youn-Chul Ryu

Division of Biotechnology, Jeju National

University, Jeju 63243, Korea

Tel: +82-64-754-3332

Fax: +82-64-725-2403

E-mail: ycryu@jejunu.ac.kr

\section{*ORCID}

Seung-Hoon Lee

https://orcid.org/0000-0001-6703-7914

Chung-Nam Kim

https://orcid.org/0000-0003-0833-0111

Kyoung-Bo Ko

https://orcid.org/0000-0002-5837-0974

Se-Pill Park

https://orcid.org/0000-0002-6965-7831

Ho-Kyoung Kim

https://orcid.org/0000-0002-7995-1129

Jun-Mo Kim

https://orcid.org/0000-0002-6934-398X

Youn-Chul Ryu

https://orcid.org/0000-0001-8940-624X

$\dagger$ These authors contributed equally to this study.

\section{Erratum}

In the published article "Comparisons of Beef Fatty Acid and Amino Acid Characteristics between Jeju Black Cattle, Hanwoo, and Wagyu Breeds. Food Sci Anim Resour 39:402-409. https://doi.org/10.5851/kosfa.2019.e33," the acknowledgements have to be modified. The editorial office will report that this amendment is made at the request of the author.

\section{Acknowledgements}

This work was supported by a grant (715003-07) from the Research Center for Production Management and Technical Development for High Quality Livestock Products through Agriculture, Food and Rural Affairs Research Center Support Program, Ministry of Agriculture, Food and Rural Affairs.

\section{References}

Lee SH, Kim CN, Ko KB, Park SP, Kim HK, Kim JM, Ryu YC. 2019. Comparisons of beef fatty acid and amino acid characteristics between Jeju black cattle, Hanwoo, and Wagyu breeds. Food Sci Anim Resour 39:402-409.

(C) Korean Society for Food Science of Animal Resources. This is an open access article distributed under the terms of the Creative Commons Attribution Non-Commercial License (http://creativecommons.org/licences/by-nc/3.0) which permits unrestricted non-commercial use, distribution, and reproduction in any medium, provided the original work is properly cited. 